\title{
Luminescence study on Eu or Tb doped lanthanum-gadolinium pyrosilicate crystal
}

\author{
Shunsuke Kurosawa ${ }^{\text {a,b,*, }}$, Toetsu Shishido a , Takamasa Sugawara ${ }^{a}$, Akiko Nomura ${ }^{a}$, Kunio Yubuta ${ }^{a}$, \\ Jan Pejchal ${ }^{\mathrm{b}, \mathrm{c}}$, Rikito Murakami ${ }^{\mathrm{a}}$, Yuui Yokota ${ }^{\mathrm{b}}$, Yasuhiro Shoji ${ }^{\mathrm{a}, \mathrm{d}}$, Yuji Ohashi ${ }^{\mathrm{a}}$, Kei Kamada ${ }^{\mathrm{b}, \mathrm{d}}$, \\ Akira Yoshikawa ${ }^{\mathrm{a}, \mathrm{b}, \mathrm{d}}$
}

${ }^{a}$ Institute for Materials Research, 2-1-1 Katahira, Aoba-ku, Sendai, Miyagi 980-8577, Japan

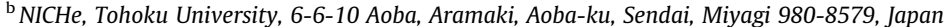

${ }^{\mathrm{c}}$ Institute of Physics AS CR, Cukrovarnicka 10, Prague 6, 16200, Czech Republic

${ }^{d}$ CEA Corporation, 6-6-40 Aoba, Aramaki, Aoba-ku, Sendai, Miyagi 980-8579, Japan

\section{A R T I C L E I N F O}

\section{Article history:}

Available online 7 January 2015

\section{Keywords:}

Scintillator

Gadolinium pyrosilicate

\begin{abstract}
A B S T R A C T
$\left(\mathrm{Eu}_{0.01}, \mathrm{Gd}_{0.90}, \mathrm{La}_{0.09}\right)_{2} \mathrm{Si}_{2} \mathrm{O}_{7}$ (Eu:La-GPS) and $\left(\mathrm{Tb}_{0.01}, \mathrm{Gd}_{0.90}, \mathrm{La}_{0.09}\right)_{2} \mathrm{Si}_{2} \mathrm{O}_{7}$ (Tb:La-GPS) crystals were grown by the floating zone method, and their optical and scintillation properties were investigated. $\mathrm{Gd}^{3+}$-to- $\mathrm{Tb}^{3+}$ or $-\mathrm{Eu}^{3+}$ energy transfer processes were found, and photo-luminescence and radio-luminescence emission spectra showed ${ }^{5} \mathrm{D}_{0}-{ }^{7} \mathrm{~F}_{i}(i=1-4)$ Eu ${ }^{3+}$ transitions in Eu:La-GPS, and ${ }^{5} \mathrm{D}_{3}-{ }^{7} \mathrm{~F}_{i}(i=3-6)$ and ${ }^{5} \mathrm{D}_{4}-{ }^{7} \mathrm{~F}_{i}$ $(i=3-6)$ transitions in Tb:La-GPS. Using these scintillators, alpha-ray imaging was possible with a CMOS camera. These materials can be used for X-ray detection as well.
\end{abstract}

(c) 2014 Elsevier B.V. All rights reserved.

\section{Introduction}

Scintillators are applied as radiation detectors in various fields such as medical imaging or high energy physics $[1,2]$. Recently, new scintillators with a crystal structure of pyrosilicate group have been studied due to good light output [3]. Among them, Ce-doped $\mathrm{Gd}_{2} \mathrm{Si}_{2} \mathrm{O}_{7}$ (Ce:GPS) was found to have good light output compared with other oxide scintillators such as $\mathrm{Ce}: \mathrm{Gd}_{2} \mathrm{SiO}_{5}$ [4-9], while the composition $\mathrm{Gd}_{2} \mathrm{O}_{3} \cdot 2 \mathrm{SiO}_{2}$ is not congruent in the $\mathrm{Gd}_{2} \mathrm{O}_{3}-\mathrm{SiO}_{2}$ system [10]. Kawamura et al. reported that the GPS phase can be stabilized by heavy Cedoping (approximately, $10 \mathrm{~mol} \%$ ) [5]. However, in such a high Ce-concentration the light output becomes lowered because of the concentration quenching. Reasonable $\mathrm{Ce}$ concentration is usually $1-\mathrm{mol} \%$ with respect to the substitution site.

The crystal growth of Ce:GPS was enabled by increasing the average ionic radius for the Gd site resulting from Ce-doping. Since $\mathrm{La}^{3+}$ ion is not luminescent and has a similar ionic radius as the $\mathrm{Ce}^{3+}$ ion [11], the substitution of La for Ce can be applied to stabilize the pyrosilicate phase. The concentration quenching can be also avoided by the reduction of Ce concentration.

* Corresponding author at: Institute for Materials Research, Tohoku University, 21-1 Katahira, Aoba-ku, Sendai 980-8577, Japan. Tel.: +81 22217 2214; fax: +81 22 2172217.

E-mail address: kurosawa@imr.tohoku.ac.jp (S. Kurosawa).
We have reported the scintillation properties of a $\left(\mathrm{Ce}_{0.01}, \mathrm{Gd}_{0.90}\right.$ $\left.\mathrm{La}_{0.09}\right)_{2} \mathrm{Si}_{2} \mathrm{O}_{7}$ (Ce:La-GPS: Cerium-doped lanthanum-gadolinium pyrosilicate) as a novel scintillator which has a high light output of roughly 35,000-42,000 photons/MeV and energy resolution (FWHM) of $\sim 5 \%$ at $662 \mathrm{keV}$, even if this sample was grown by floating zone (FZ) method [12,13]. Moreover, Tsubota et al. also reported the scintillation properties of a $\left(\mathrm{Ce}_{0.025}, \mathrm{Gd}_{0.875}, \mathrm{La}_{0.1}\right)_{2}$ $\mathrm{Si}_{2} \mathrm{O}_{7}$ crystal grown by the top-seeded solution growth method, whose light yield was 1.2 times larger than that of NaI:Tl [14]. Here, NaI:Tl has a light output of roughly 43,000-45,000 photons/MeV [15-17]. Furthermore, the light output of the Ce:La-GPS was found constant in the temperature range from $0{ }^{\circ} \mathrm{C}$ to $150{ }^{\circ} \mathrm{C}[18]$.

In addition, optical and scintillation properties of Pr-doped pyrosilicate-group crystals such as Pr:GPS, Pr:La-GPS have been studied $[19,20]$, because Pr-doped scintillators are expected to have shorter scintillation decay time originating from $5 \mathrm{~d}-4 \mathrm{f}$ transition of $\mathrm{Pr}^{3+}$. Although the pyrosilicate-group crystals with other rare-earth dopants employing $4 \mathrm{f}-4 \mathrm{f}$ luminescence are not expected to have fast decay time, these materials can be used as $\mathrm{X}$-ray detection scintillators. Especially, scintillation emission wavelength of $\mathrm{Eu}$ or $\mathrm{Tb}$ doped crystals very well matches the sensitivity region of a charge coupled device (CCD) or a complementary metal-oxide semiconductor (CMOS) camera with high quantum efficiency, which is roughly within $500-700 \mathrm{~nm}$ $[21,22]$. In this paper, we show the optical and scintillation 
properties of $\left(\mathrm{Eu}_{0.01}, \mathrm{Gd}_{0.90}, \mathrm{La}_{0.09}\right)_{2} \mathrm{Si}_{2} \mathrm{O}_{7}$ (Eu:La-GPS) and $\left(\mathrm{Tb}_{0.01}\right.$, $\left.\mathrm{Gd}_{0.90}, \mathrm{La}_{0.09}\right)_{2} \mathrm{Si}_{2} \mathrm{O}_{7}$ (Tb:La-GPS).

\section{Materials and experimental methods}

$\left(\mathrm{Eu}_{0.01}, \mathrm{Gd}_{0.90}, \mathrm{La}_{0.09}\right)_{2} \mathrm{Si}_{2} \mathrm{O}_{7}$ (Eu:La-GPS) and $\left(\mathrm{Tb}_{0.01}, \mathrm{Gd}_{0.90}\right.$, $\left.\mathrm{La}_{0.09}\right)_{2} \mathrm{Si}_{2} \mathrm{O}_{7}$ (Tb:La-GPS) crystals were grown by the floating zone method (FZ) under argon atmosphere. The starting materials were highly pure $99.99 \% \mathrm{Eu}_{2} \mathrm{O}_{3}, \mathrm{~Tb}_{2} \mathrm{O}_{3}, \mathrm{La}_{2} \mathrm{O}_{3}, \mathrm{Gd}_{2} \mathrm{O}_{3}$ and $\mathrm{SiO}_{2}$ powders, which were used to prepare two sintered bars. Then, the sintered bars were set in the FZ apparatus and melted by the focused heating with a pair of high intensity infra-red lamps and ellipsoidal mirrors. Both Eu:La-GPS and Tb:La-GPS crystals were grown under the pulling down rate $1-5 \mathrm{~mm} / \mathrm{h}$ and rotation rate $20 \mathrm{rpm}$. The asgrown crystals were cut into a 1-mm thickness and then polished to a mirror gloss.

After polishing, transmittance was measured with spectrophotometer (V-530, JASCO). Emission and absorption wavelengths of the samples were measured with the following setup as shown in Fig. 1(a); each sample, RE:La-GPS (RE = Eu, Tb), was excited by monochromatic UV photons using a Xenon lamp (150 W) and a Monochromator (Sp2150i, Princeton Instruments) controlled by a computer. Using an optical fiber, the sample was excited with the UV light in an integrating sphere. The emitted photons were detected using a spectrophotometer (PMA-12, Hamamatsu Photonics KK), consisting of Si-semiconductors. Moreover, temperature dependences of quantum yield within $30-175^{\circ} \mathrm{C}$ range were evaluated using a heater as shown in Fig. 1(b).

The radio-luminescence spectrum for each sample was obtained under X-ray irradiation. Here, the X-rays were generated by a Cu target under $40 \mathrm{kV}$ and $40 \mathrm{~mA}$, and the emission spectrum was measured using a CCD camera (DU-420-OE, Andor). Moreover, scintillation imaging was tested for these crystals with $5.5 \mathrm{MeV}$ alpha ray irradiation from an ${ }^{241} \mathrm{Am}(\sim 4 \mathrm{MBq})$ source using a CMOS camera (ORCA-Flash4.0 V2, Hamamatsu Photonics K.K.). The detail of the CMOS imaging camera is described in Ref. [21,22].

\section{Results and discussion}

Fig. 2 shows $\left(\mathrm{Eu}_{0.01}, \mathrm{Gd}_{0.90}, \mathrm{La}_{0.09}\right)_{2} \mathrm{Si}_{2} \mathrm{O}_{7}$ (Eu:La-GPS) and $\left(\mathrm{Tb}_{0.01}\right.$, $\left.\mathrm{Gd}_{0.90}, \mathrm{La}_{0.09}\right)_{2} \mathrm{Si}_{2} \mathrm{O}_{7}$ (Tb:La-GPS) single crystals grown by the FZ
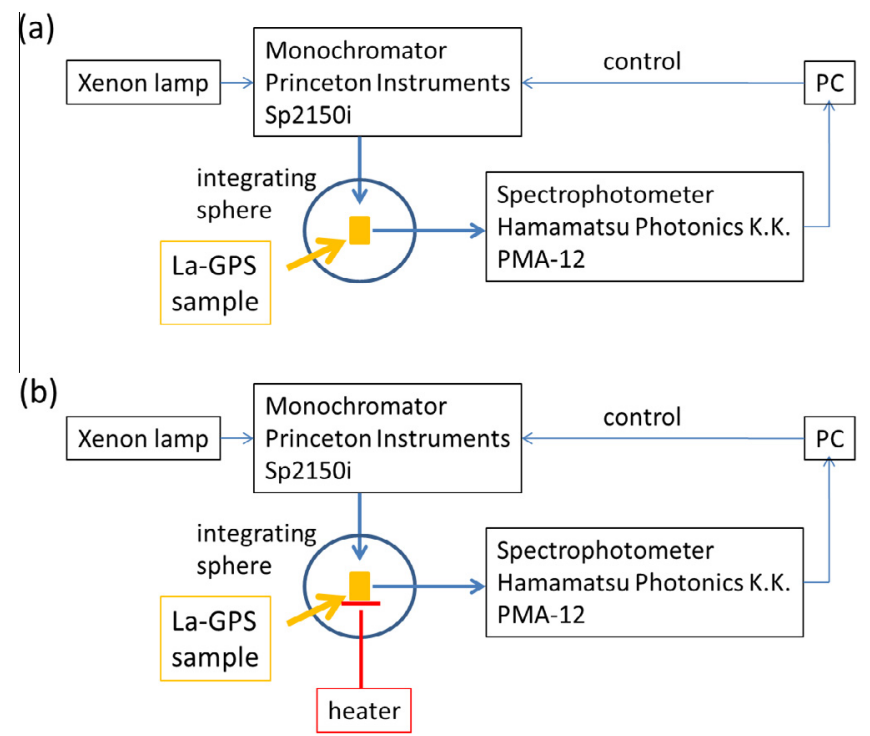

Fig. 1. Schematic view of set up for photo-luminescence measurement (a) and quantum yield measurement at several temperature with a heat device (b). (a)

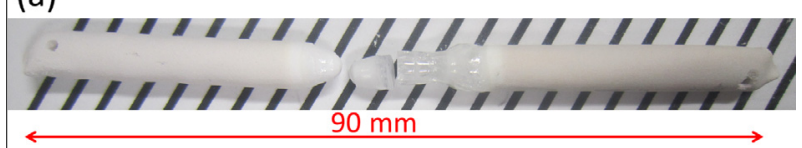

(b)

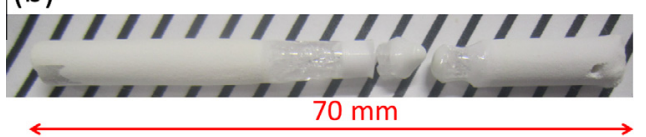

(c)

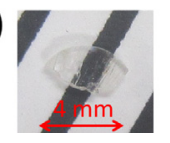

(d)

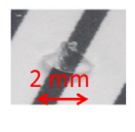

Fig. 2. Photographs of $\left(\mathrm{Eu}_{0.01}, \mathrm{Gd}_{0.90}, \mathrm{La}_{0.09}\right)_{2} \mathrm{Si}_{2} \mathrm{O}_{7}$ (Eu:La-GPS) (a), $\left(\mathrm{Tb}_{0.01}, \mathrm{Gd}_{0.90}\right.$ $\left.\mathrm{La}_{0.09}\right)_{2} \mathrm{Si}_{2} \mathrm{O}_{7}$ (Tb:La-GPS) (b) crystals grown by the floating zone method, and polished Eu:La-GPS (c) and Tb:La-GPS (d) samples for measurement of optical properties.

method. Transmittance spectra of the samples at 200-900 nm are shown in Fig. 3. The broad absorption band for the Tb-doped sample in $210-240 \mathrm{~nm}$ range can be ascribed to the $4 \mathrm{f}-5 \mathrm{~d}$ transition of $\mathrm{Tb}^{3+}$, while the transmittance drop below $250 \mathrm{~nm}$ for the Eu-doped one can be ascribed to the charge transfer band (CTB) of $\mathrm{Eu}^{3+}-\mathrm{O}^{2-}[23,24]$. Additionally, spectra for both samples had sharp lines related to the $4 \mathrm{f}-4 \mathrm{f}$ transitions of $\mathrm{Gd}^{3+}:{ }^{8} \mathrm{~S}_{7 / 2}{ }^{6}{ }^{6} \mathrm{I}_{\mathrm{i}}$ and ${ }^{8} \mathrm{~S}_{7 / 2}{ }^{6} \mathrm{P}_{j}$, where $i=13 / 2,11 / 2, \ldots, 7 / 2, j=7 / 2,5 / 2$, around 280 and $310 \mathrm{~nm}$, respectively. Photo-luminescence emission wavelength as a function of excitation wavelength for the each sample is shown in Fig. 4. Excitation peaks for both samples located at around 280 and $310 \mathrm{~nm}$ corresponded to the absorption peaks of $\mathrm{Gd}^{3+}$, which is a proof of the energy transfer from $\mathrm{Gd}^{3+}$ to $\mathrm{Tb}^{3+}$ or $\mathrm{Eu}^{3+}$. Also the energy transfer from $\mathrm{Gd}^{3+}$ to $\mathrm{Eu}^{3+}$ or $\mathrm{Tb}^{3+}$ were reported for other materials such as $\mathrm{Eu}^{3+}: \mathrm{Gd}_{2} \mathrm{SiO}_{5}$ [25], gadolinium-terbium-doped silicate glasses [26].

Fig. 5 shows emission spectra of Eu:La-GPS and Tb:La-GPS excited by 280 and $310-\mathrm{nm}$ photons, respectively. The spectrum for Eu:La-GPS contains $4 \mathrm{f}-4 \mathrm{f}$ transitions of $\mathrm{Eu}^{3+}:{ }^{5} \mathrm{D}_{0}{ }^{-} \mathrm{F}_{i}(i=1-4)$, and that for Tb:La-GPS contains the $\mathrm{Tb}^{3+}$ transitions including ${ }^{5} \mathrm{D}_{3}-{ }^{7} \mathrm{~F}_{j}(j=3-6)$ and ${ }^{5} \mathrm{D}_{4}-{ }^{7} \mathrm{~F}_{k}(k=3-6)$. Quantum yields of Eu:LaGPS and Tb:La-GPS at room temperature were determined to be $\sim 43 \%$ for ${ }^{5} \mathrm{D}_{0}-{ }^{7} \mathrm{~F}_{2}$ emission of $\mathrm{Eu}^{3+}(600-635 \mathrm{~nm}, 273$ to $285-\mathrm{nm}$ excitation) and $\sim 57 \%$ for ${ }^{5} \mathrm{D}_{4}{ }^{-}{ }^{7} \mathrm{~F}_{5}$ emission of $\mathrm{Tb}^{3+}(530-570 \mathrm{~nm}$, 298 to 320-nm excitation), respectively. The temperature dependences of these quantum yields are shown in Fig. 6. Quantum yields of Eu:La-GPS and Tb:La-GPS were degraded at higher temperatures. Fig. 7 shows radio-luminescence spectra for both samples excited by $\mathrm{X}$ rays. The emission peaks corresponded to

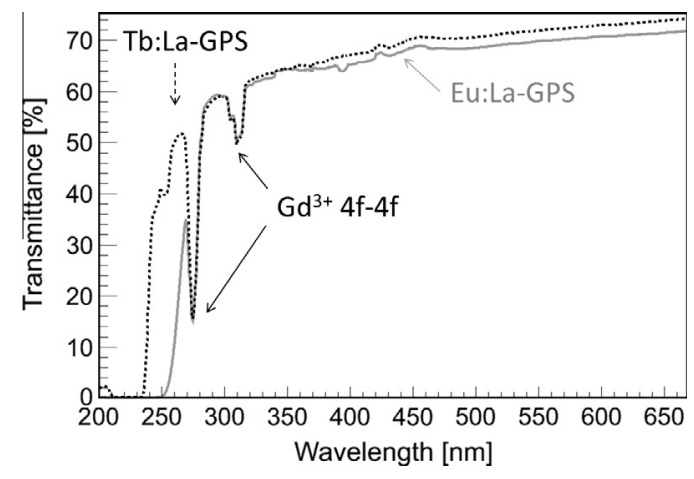

Fig. 3. Transmittance spectra of Eu:La-GPS and Tb:La-GPS 

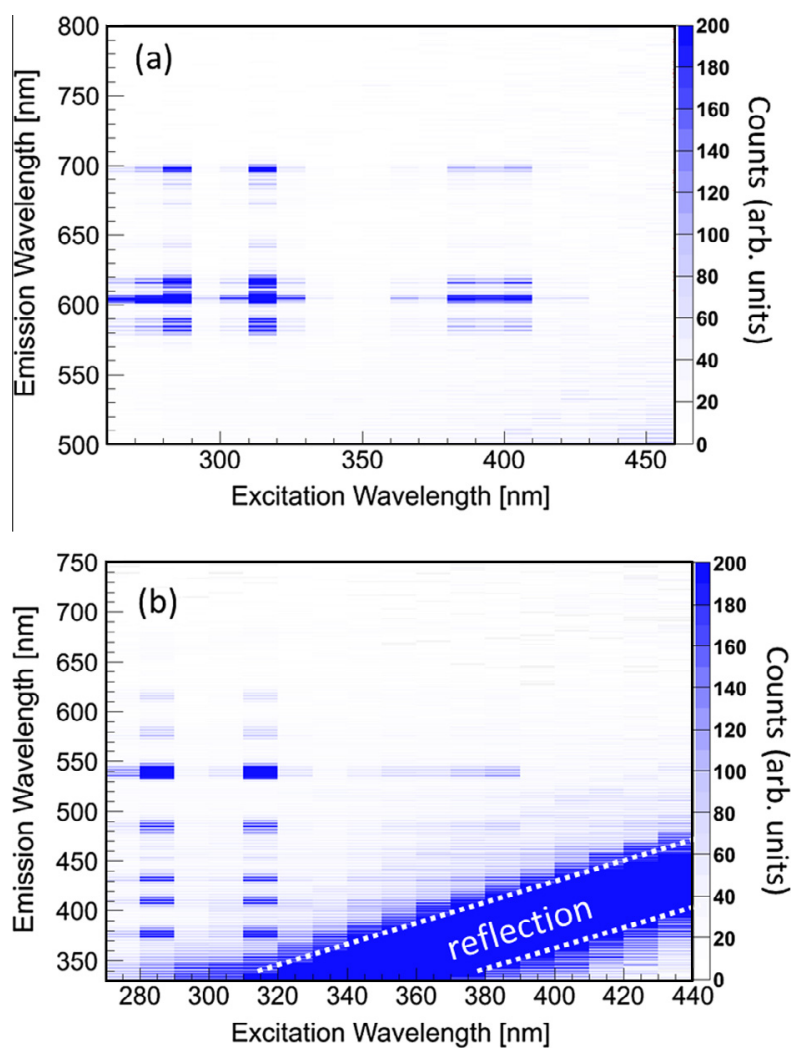

Fig. 4. Emission wavelength as a function of excitation wavelength for Eu:La-GPS (a) and Tb:La-GPS (b).
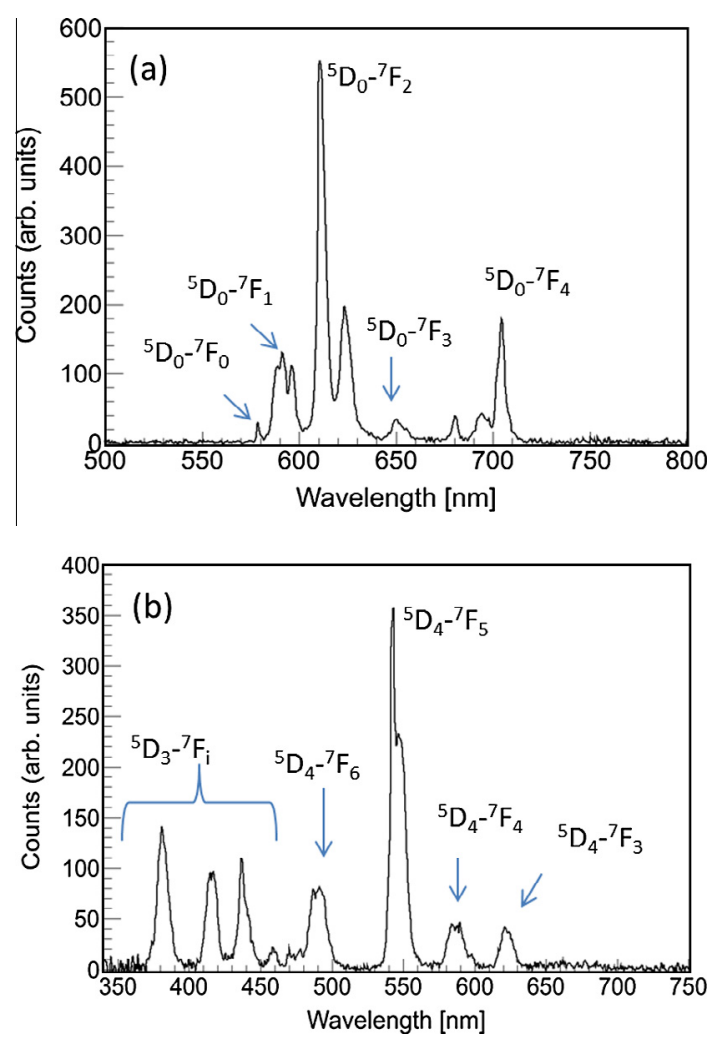

Fig. 5. Emission spectra of Eu:La-GPS (a) and Tb:La-GPS (b).

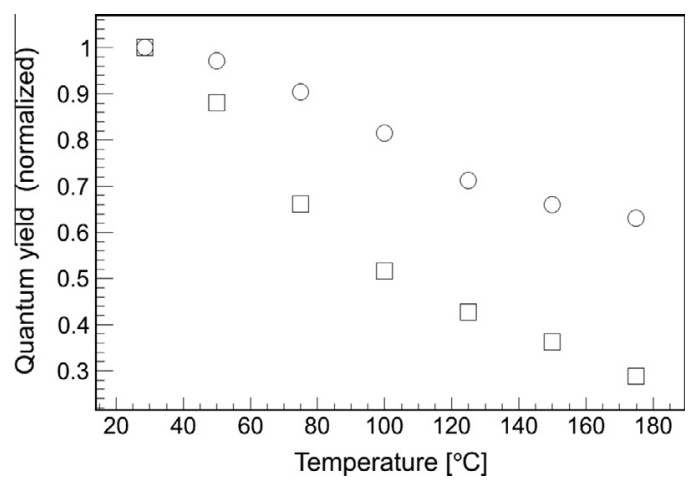

Fig. 6. Quantum yields as a function of temperature for Eu:La-GPS (open circles) and Tb:La-GPS (open squares). The values are normalized to the values at room temperature $\left(28.5^{\circ} \mathrm{C}\right)$.

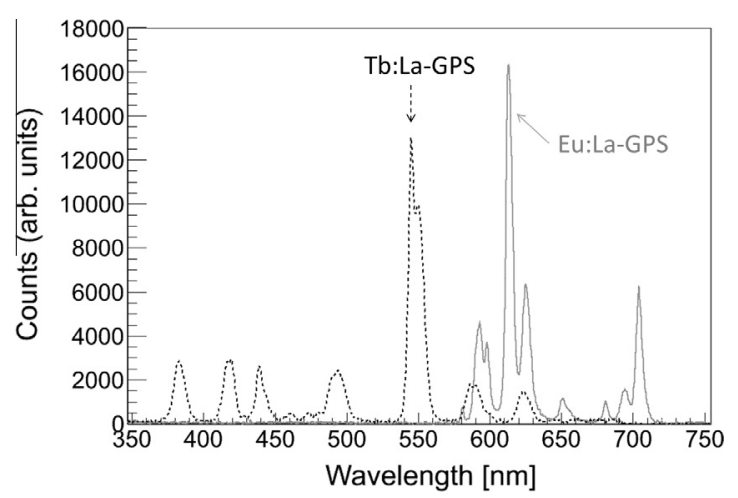

Fig. 7. Radio-luminescence spectra of Eu:La-GPS and Tb:La-GPS excited by X rays. (a)

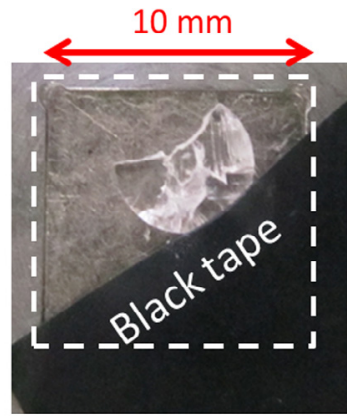

(b)

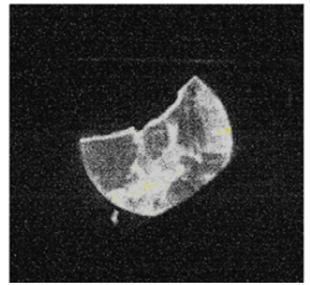

(c)

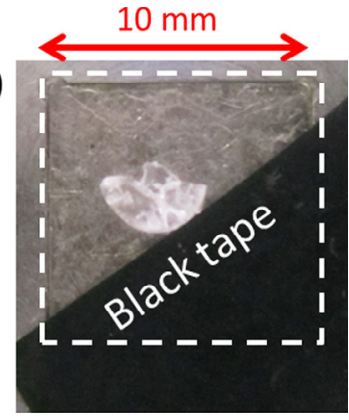

(d)

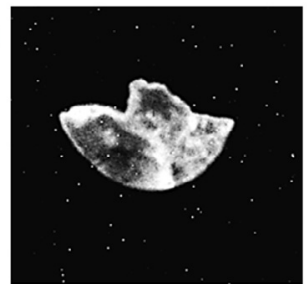

Fig. 8. Photo graph of Eu:La-GPS (a) and Tb:La-GPS (c) crystals on the ${ }^{241} \mathrm{Am}$ source, where white dotted squares denote radiation region, and imaging results of Eu:La-GPS (b) and Tb:La-GPS (d).

the photo-luminescence emission peaks. The results of imaging tests for Eu:La-GPS and Tb:La-GPS are shown in Fig. 8, where exposure times were $10 \mathrm{~s}$. Here, the crystal samples had some cracks which are different from the samples for the above measurements for optical and scintillation properties, and these cracks were found in the alpha-ray images. 


\section{Conclusions}

We succeeded in growing $\left(\mathrm{Eu}_{0.01}, \mathrm{Gd}_{0.90}, \mathrm{La}_{0.09}\right)_{2} \mathrm{Si}_{2} \mathrm{O}_{7}$ (Eu:LaGPS) and $\left(\mathrm{Tb}_{0.01}, \mathrm{Gd}_{0.90}, \mathrm{La}_{0.09}\right)_{2} \mathrm{Si}_{2} \mathrm{O}_{7}$ (Tb:La-GPS) crystals by the floating zone method. The photo-luminescence emission and excitation spectra showed $\mathrm{Gd}^{3+}$-to- $\mathrm{Tb}^{3+}$ or $-\mathrm{Eu}^{3+}$ energy transfer processes; ${ }^{8} \mathrm{~S}_{7 / 2}{ }^{6} \mathrm{I}_{i}$ and ${ }^{8} \mathrm{~S}_{7 / 2}{ }^{-6} \mathrm{P}_{j},(i=13 / 2,11 / 2, \ldots, 7 / 2, j=7 / 2,5 / 2$ lines of $\mathrm{Gd}^{3+}$ were found for the excitation spectra for the corresponding $\mathrm{Eu}^{3+}$ and $\mathrm{Tb}^{3+}$ emission lines, which were ${ }^{5} \mathrm{D}_{0^{-}}{ }^{7} \mathrm{~F}_{i}$ $(i=1-4)$ transitions for $\mathrm{Eu}^{3+}$ in Eu:La-GPS, and ${ }^{5} \mathrm{D}_{3}-{ }^{7} \mathrm{~F}_{i}(i=3-6)$ and ${ }^{5} \mathrm{D}_{4^{-}}{ }^{7} \mathrm{~F}_{i}(i=3-6)$ transitions for $\mathrm{Tb}^{3+}$ in Tb:La-GPS were found. Scintillation light was also observed for both crystals, and the radioluminescence emission peaks were corresponding to the photo-luminescence emission peaks. Moreover, we succeeded in obtaining some images using a CMOS camera, so we can conclude that these materials can be used as X-ray imaging scintillators.

\section{Acknowledgments}

This work is partially supported by (i) Japan Society for the Promotion of Science (JSPS) Research Fellowships for Young Scientists (S. Kurosawa), (ii) the funding program for next generation worldleading researchers, JSPS, (iii) Development of Systems and Technology for Advanced Measurement and Analysis, Japan Science and Technology Agency (JST) (iv) Adaptable \& Seamless Technology Transfer Program through Target-driven R\&D (A-STEP), JST, (v) the Association for the Progress of New Chemical Technology, (vi) The Murata Science Foundation, (vii) Nippon Sheet Glass Foundation for Materials Science and Engineering and (vii) Tonen General Sekiyu Foundation. In addition, we would like to thank following persons for their support: Mr. Yoshihiro Nakamura of Institute of Multidisciplinary Research for Advanced Materials (IMRAM), Tohoku University and Yoshihiro Murakami, Mr. Hiroshi Uemura, Ms. Keiko Toguchi, Ms. Megumi Sasaki, Ms. Yuka Takeda and Ms. Kuniko Kawaguchi of IMR/Tohoku University.

\section{References}

[1] C.W.E. van Eijk, Phys. Med. Biol. 47 (2002) R85.

[2] C. Rozsa, R. Dayton, P. Raby, M. Kusner, R. Schreiner, IEEE Trans. Nucl. Sci. 37 (1990) 966.
[3] L. Pidol, A. Kahn-Harari, B. Viana, E. Virey, B. Ferrand, P. Dorenbos, J.T.M. de Haas, C.W.E. van Eijk, IEEE Trans. Nucl. Sci. 51 (2004) 1084.

[4] J.H. Kaneko, N. Susa, S. Tsuchida, M. Watanabe, S. Miura, T. Mizuno, Y. Yamauchi, M. Hashiba, T. Oku, A. Homma, F. Fujita, T. Ino, M. Furusaka, T. Sawamura, H.M. Shimizu, Y. Kiyanagi, Nucl. Instrum. Methods Phys. Res. A529 (2004) 307-309.

[5] S. Kawamura, J. H. Kaneko, M. Higuchi, T. Yamaguchi, J. Haruna, Y. Yagi, K. Susa, F. Fujita, A. Homma, S. Nishiyama, H. Ishibashi, K. Kurashige and M. Furusaka, in: IEEE Nuclear Science Symposium Conference Record, San Diego, USA, 29 October-5 November 2006, pp. 1160-1163.

[6] S. Kawamura, J.H. Kaneko, M. Higuchi, F. Fujita, A. Homma, J. Haruna, S. Saeki, K. Kurashige, H. Ishibashi, M. Furusaka, Nucl. Instrum. Methods Phys. Res. A583 (2007) 356-359.

[7] I. Gerasymov, O. Sidletskiy, S. Neicheva, B. Grinyov, V. Baumer, E. Galenin, K. Katrunov, S. Tkachenko, O. Voloshina, A. Zhukov, J. Cryst. Growth 318 (2011) 805-808.

[8] V. Baumer, I. Gerasymov, O. Sidletskiy, O. Voloshina, S. Neicheva, J. Alloys Compd. 509 (2011) 8478-8482.

[9] Oleg Sidletskiy, Vyacheslav Baumer, Iaroslav Gerasymov, Boris Grinyov, Konstantin Katrunov, Nikolai Starzhinsky, Oleg Tarasenko, Vladimir Tarasov, Sergiy Tkachenko, Olesya Voloshina, Olga Zelenskaya, Radiat. Meas. 45 (2010) 365-368.

[10] N.A. Toropov, F.Ya. Glakhov, S.F. Konovalova, Russ. Chem. Bull. 10 (1961) 497501.

[11] R.D. Shannon, Acta Cryst. A32 (1976) 751-767.

[12] A. Suzuki, S. Kurosawa, T. Shishido, J. Pejchal, Y. Yokota, Y. Futami, A. Yoshikawa, App. Phys. Exp. 5 (2012) 102601.

[13] Shunsuke Kurosawa, Toetsu Shishido, Akira Suzuki, Jan Pejchal, Yuui Yokota, Akira Yoshikawa, Nucl. Instrum. Methods A 744 (2014) 30-34.

[14] Youichi Tsubota, Junichi H. Kaneko, Mikio Higuchi, Moyuru Minagawa, Hiroyuki Ishibashi, Opt. Mater. 36 (2014) 665-669.

[15] I. Holl, E. Lorenz, G. Mageras, IEEE Trans. Nucl. Sci. 35 (1988) 105-109.

[16] E. Sakai, IEEE Trans. Nucl. Sci. 34 (1987) 418-422.

[17] J.T.M.d. Haas, P. Dorenbos, IEEE Trans. Nucl. Sci. 55 (2008) 1086-1092.

[18] Shunsuke Kurosawa, Toetsu Shishido, Takamasa Sugawara, Akiko Nomura, Kunio Yubuta, Akira Suzuki, Rikito Murakami, Jan Pejchal, Yuui Yokota, Kei Kamada, Akira Yoshikawa, Nucl. Instrum. Methods A 772 (2015) 72-75.

[19] Youichi Tsubota, Junichi H. Kaneko, Mikio Higuchi, Sohan Kawamura, Shusuke Nishiyama, Fumiyuki Fujita, Shunsuke Ueda, Kazuhisa Kurashige, Hiroyuki Ishibashi, Akira Homma, Michihiro Furusaka, Prog. Nucl. Sci. Technol. (2011) 288-291.

[20] Rikito Murakami, Shunsuke Kurosawa, Toetsu Shishido, Takamasa Sugawara, Akiko Nomura, Kunio Yubuta, Akira Suzuki, Yasuhiro Shoji, Yuji Ohashi, Jan Pejchal, Kei Kamada, Yuui Yokota and Akira Yoshikawa, Jpn. J. Appl. Phys. (submitted for publication).

[21] Hamamatsu K.K. Catalog <http://www.hamamatsu.com/eu/en/community/ life_science camera/product/search/C11440-42U/index.html>.

[22] S. Kurosawa, Y. Shoji, Y. Yokota, A. Yoshikawa, J. Instrum. 9 (7) (2014) C07015.

[23] Liya Zhou, Wallace C.H. Choy, Jianxin Shi, Menglian Gong, Hongbin Liang, Mater. Chem. Phys. 100 (2006) 372-374.

[24] Y.H. Zhou, J. Lin, S.B. Wang, H.J. Zhang, Opt. Mater. 20 (2002) 13-20.

[25] Yonghu Chen, Bo Liu, Chaoshu Shi, Marco Kirm, Marcus True, Sebastian Vielhauer, Georg Zimmerer, J. Phys.: Condens. Matter 17 (2005) 1217-1224.

[26] D. He, C. Yu, J. Cheng, S. Li, L. Hu, J. Rare Earths 29 (1) (2011) 48-51. 